\title{
The cyclooxygenase-2/prostaglandin E2 pathway is involved in the somatostatin-induced decrease of epileptiform bursting in the mouse hippocampus
}

Chiara Ristori a,b, Maurizio Cammalleri a, Davide Martini a,c, Barbara Pavan b, Giovanni Casini c, Davide Cervia a,c, Paola Bagnoli a,*

a Department of Biology e Unit of General Physiology, University of Pisa, via San Zeno 31, 56127 Pisa, Italy

b Department of Biology e General Physiology Section, University of Ferrara, via L. Borsari 46, 44100 Ferrara, Italy

c Department of Environmental Sciences, University of Tuscia, largo dell’Universita`snc, blocco D, 01100 Viterbo, Italy

* Corresponding author. Tel.: 39050221 1422; fax: 390502211421.

E-mail address: pbagnoli@biologia.unipi.it (P. Bagnoli).

Abstract

The neuromodulatory peptide somatostatin-14 (SRIF) plays an important inhibitory role in epilepsy, but little is known on the signalling mechanisms coupled to this effect of SRIF. We have previously demonstrated that SRIF induces reduction of epileptiform bursting in a model of interictal-like activity in mouse hippocampal slices. In this same model, we investigated whether the cyclooxygenase 2 (COX-2)/prostaglandin E2 (PGE2) pathway is part of those signalling mechanisms mediating SRIF anti-epileptic actions. Both the expression of COX-2 (mRNA and protein) and the endogenous release of PGE2 increased in concomitance with epileptiform bursting. In particular, $\mathrm{COX}-2$ protein increased in $\mathrm{CA} 1 / \mathrm{CA} 3$ pyramidal layer and in the granular layer of the dentate gyrus. In addition, the selective inhibition of COX-2 by NS-398 markedly decreased endogenous PGE2 release induced by epileptiform bursting and the epileptiform bursting itself. Similar effects on epileptiform bursting were obtained with another COX-2 inhibitor, i.e., meloxicam. SRIF application counteracted the increase of both COX-2 expression and PGE2 release which occurred in concomitance with epileptiform bursting. Interestingly, SRIF and NS-398 comparably reduced epileptiform bursting in a non-additive manner and PGE2 abolished the 
inhibitory effect of SRIF on epileptiform bursting. These results demonstrate that: i) the COX2/PGE2 pathway facilitates epileptiform bursting; and ii) SRIF exerts an anti-epileptic role by coupling to the COX-2/PGE2 pathway. In conclusion, we have identified a key set of signalling events that underlie anti-convulsant effects of SRIF in a mouse model of hippocampal bursting, thus providing useful data not only to identify alternative intervention points for the modulation of SRIF function, but also to exploit new chemical space for drug-like molecules.

Keywords: Neuropeptide signalling; Epilepsy; Prostaglandin E2; COX-2 inhibitors; Hippocampal slices; Electrophysiological recordings

\section{Introduction}

The peptide somatostatin-14, or SRIF (somatotropin release inhibiting factor), is abundantly expressed in mammalian neurons. It is considered as a neuromodulatory agent in the central nervous system, and a variety of studies provide the basis for the use of SRIF analogues as therapeutics in various psychiatric and neurological disorders (Cervia and Bagnoli, 2007; Weckbecker et al., 2003). SRIF is expressed by hippocampal interneurons, while functional data of the rodent hippocampus have provided compelling evidence that SRIF plays an important role in epilepsy (Binaschi et al., 2003; Jinno and Kosaka, 2004; Matyas et al., 2004; Vezzani and Hoyer, 1999). Generally, in selected regions of the hippocampus, the acute effects of SRIF compounds on synaptic transmission are largely inhibitory (Binaschi et al., 2003; Tallent and Siggins, 1999; Vezzani and Hoyer, 1999). In addition, SRIF inhibition of epileptiform bursting has been demonstrated in mouse CA1 and CA3 regions (Cammalleri et al., 2004, 2006; Cervia et al., 2005a). There is a general agreement that the pleiotropic functions of SRIF are a result of the multiple signalling actions of its five G-protein coupled receptors, but our current understanding of such signalling in native cells/tissues reflects a rather complicated picture (Cervia and Bagnoli, 2007). In the mouse hippocampus, for instance, the SRIF-mediated reduction of epileptiform bursting has been shown to parallel the SRIF-mediated inhibition of adenylyl cyclase activity (Cammalleri et al., 2004, 2006), however, the signalling mechanisms mediating SRIF actions on hippocampal epileptiform activity remain largely to be clarified.

Specific signalling mechanisms have been implicated in hippocampal excitability, including epileptiform activity (McNamara et al., 2006). For instance, arachidonic acid (AA) is released from neuronal membrane phospholipids during seizures and the phospholipase A2 (PLA2)/AA/cyclooxygenases (COXs)/prostaglandins (PGs) cascade appears to play a key role in 
epileptogenesis (for a review see Cole- Edwards and Bazan, 2005; Hewett et al., 2006; Phillis et al., 2006). The PLA2 enzyme hydrolyzes triglycerol to form AA. Free AA is a substrate for different enzymes, including COXs (which exists in two different isoforms: COX-1 and COX-2). In the central nervous system, COX-1 has an ubiquitary distribution in both glia and neurons, whereas COX-2 is constitutively expressed primarily in neurons (Hewett et al., 2006). In particular, constitutive COX-2 protein has been found in selected brain regions, including the hippocampus, where it appears to be coupled to excitatory neuronal activity, and produces PGs required for normal neuronal functions. Among PGs, PGE2 plays a central role in the modulation of hippocampal activity (Chen and Bazan, 2005b). In addition, an important role of COX-2 and the COX-2-generated PGE2 in hippocampal synaptic signalling and seizures has been recently documented (Chen and Bazan, 2005a; Chen et al., 2002; Kawaguchi et al., 2005; Sang et al., 2005; Takemiya et al., 2003, 2006; Tu and Bazan, 2003; Voutsinos-Porche et al., 2004). In the present study, our hypothesis was that the COX-2 pathway is part of those signalling mechanisms mediating the SRIF inhibition of mouse hippocampal activity. Supporting this hypothesis, an important component in transduction mechanisms of SRIF in native cell/tissues as well as in recombinant systems is the modulation of PLA2 pathway (Cervia and Bagnoli, 2007; Cervia et al., 2005b). In our work, we used a well-established model of epileptiform bursting (interictal-like activity) induced in mouse hippocampal slices by $\mathrm{Mg} 2 \mathrm{p}$-free medium with 4aminopyridine (0 Mg2p/ 4-AP) (Cammalleri et al., 2004, 2006; Cervia et al., 2005a). In this model, we first evaluated whether the expression of COX-2 and the endogenous release of PGE2 are modified by $0 \mathrm{Mg} 2 \mathrm{p} / 4-\mathrm{AP}$ either alone or in combination with SRIF. We then studied the effects of COX-2 inhibition on both PGE2 release and epileptiform bursting as well as the possible correlation between COX-2/PGE2 modulation and SRIF inhibitory action on epileptiform bursting.

\section{Methods}

\subsection{Animals}

Experiments were performed on 64 mice (C57BL/6 strain) of both sexes at $6 \mathrm{e} 8$ weeks after birth (20e30 g body weight). Animals were kept in a regulated environment $\left(23\right.$ _ 1 _, $50 \_5 \%$ humidity) with a $12 \mathrm{~h}$ light/dark cycle (lights on at 8 a.m.) with food and water ad lib. In all experiments, mice were anaesthetised with halothane (4\%). Experiments were performed in compliance with the Italian law on animal care N_ 116/1992 and in accordance with the European Community Council Directive (EEC/609/86). All efforts were made to reduce both animal suffering and the number of animals used. 


\subsection{Preparation of hippocampal slices}

Slices of dorsal hippocampus were prepared as previously described (Cammalleri et al., 2004, 2006; Cervia et al., 2005a). Briefly, mice were anaesthetised and decapitated. Their brains were rapidly removed, placed in ice-cold artificial cerebrospinal fluid (aCSF) and gassed with 95\% O2 and 5\% $\mathrm{CO} 2$. The composition of aCSF was (in $\mathrm{mM}$ ): $\mathrm{NaCl}, 130 ; \mathrm{KCl}, 3.5 ; \mathrm{NaH} 2 \mathrm{PO} 4,1.25 ; \mathrm{MgSO} 4$ 7H2O, 1.5; $\mathrm{CaCl} 2$ 2H2O, 2; NaHCO3, 24; glucose, 10; pH 7.4. Transverse hippocampal slices (400 $\mathrm{mm}$ ) were prepared with the use of a vibratome (Campden Instruments, Loughborough, UK) and incubated for $1 \mathrm{~h}$ at room temperature in aCSF. For experiments in basal conditions, hippocampal slices were then placed in aCSF for additional $3 \mathrm{~h}$. Alternatively, they were placed for $3 \mathrm{~h}$ in 0 $\mathrm{Mg} 2 \mathrm{p} / 4-\mathrm{AP}$ consisting of $\mathrm{Mg} 2 \mathrm{p}$-free aCSF with $50 \mathrm{mM}$ 4-AP to induce epileptiform bursting (interictal-like activity) in agreement with previous works (Cammalleri et al., 2004, 2006; Cervia et al., 2005a; Sanna et al., 2000). Indeed, depletion of extracellular Mg2p from hippocampal slices results in enhancement of synaptically evoked responses in CA1 and CA3 regions and the appearance of spontaneous paroxysmal depolarisation shifts in both areas, whereas 4-AP induces epileptiform activity by enhancing the release of excitatory and inhibitory amino acids (Avoli, 2001). When indicated, the COX inhibitors NS-398 or meloxicam were applied $2 \mathrm{~h}$ and $20 \mathrm{~min}$, respectively, before the end of the incubation in $0 \mathrm{Mg} 2 \mathrm{p} / 4-\mathrm{AP}$.

\subsection{Semi-quantitative reverse transcription (RT)-PCR}

After $3 \mathrm{~h}$ slice incubation in aCSF or $0 \mathrm{Mg} 2 \mathrm{p} / 4-\mathrm{AP}$, the medium was replaced with fresh medium consisting of aCSF, $0 \mathrm{Mg} 2 \mathrm{p} / 4-\mathrm{AP}$ or $0 \mathrm{Mg} 2 \mathrm{p} / 4-\mathrm{AP} \mathrm{p}$ SRIF for additional $20 \mathrm{~min}$. For each experimental condition, 4 slices from different animals were then collected and total RNA extraction was performed in Trizol reagent (Invitrogen, Milano, Italy). After solubilization in diethyl pyrocarbonate-treated water, total RNA was quantified by Bio-Rad SmartSpec 3000 spectrophotometer (Hercules, CA, USA). First-strand cDNA was generated from $2 \mathrm{mg}$ of total RNA using random primers and the reverse transcriptase of Moloney murine leukemia virus (Invitrogen, Milano, Italy). As shown in Table 1, primer pairs for COX-2 were designed to hybridise to unique regions of the respective gene sequence. Primers for cyclophilin B, a stable mRNA during epilepsy (Cammalleri et al., 2004, 2006), was used as an internal standard. The PCR reactions were carried out using $1 \mathrm{ml}$ of cDNA in a $25 \mathrm{ml}$ total volume of PCR buffer (Invitrogen, Milano, Italy), containing $1.5 \mathrm{mM} \mathrm{MgCl} 2,200 \mathrm{mM}$ dNTPs, and $400 \mathrm{nM}$ of appropriate primers. Taq polymerase (0.5 U, Invitrogen) was also added. The amplification reactions were carried out in a thermal gradient cycler (Bio-Rad, Hercules, CA, USA) for 30 cycles. Each cycle consisted of denaturation for $60 \mathrm{~s}$ at 94 _C, annealing for $60 \mathrm{~s}$ at 55 _C (COX-2) or 60 _C (cyclophilin B), and an extension 
for $60 \mathrm{~s}$ at 72 _C. A final extension step at 72 _C for 10 min terminated the amplification. For each amplification, two types of controls were performed: (i) RT-PCR mixture with no reverse transcriptase to control for genomic DNA contamination; and (ii) PCR mixture with no cDNA template, to check for possible external contamination. A $5 \mathrm{ml}$ sample of the PCR reaction was electrophoresed on an ethidium bromide-containing $2 \%$ agarose gel by the use of the Bio-Rad Subcell GT system. After migration, bands corresponding to the amplified products were analysed with Gel Doc 2000 System equipped with Quantity One software (Bio-Rad). Semi-quantitative analysis of PCR products was performed by measuring the optical intensity of the bands corresponding to COX-2 with respect to the optical intensity of the band corresponding to the respective cyclophilin B.

\subsection{Immunohistochemistry}

After $3 \mathrm{~h}$ slice incubation in aCSF or $0 \mathrm{Mg} 2 \mathrm{p} / 4-\mathrm{AP}$, the medium was replaced with fresh medium consisting of aCSF, $0 \mathrm{Mg} 2 \mathrm{p} / 4-\mathrm{AP}$ or $0 \mathrm{Mg} 2 \mathrm{p} / 4-\mathrm{AP} \mathrm{p}$ SRIF for additional $20 \mathrm{~min}$. Using published protocols (Cammalleri et al., 2006), the hippocampal slices were then fixed for $1 \mathrm{~h}$ in $4 \%$ paraformaldehyde in $0.1 \mathrm{M}$ phosphate buffer $(\mathrm{PB})$ at 4 _C. They were then rinsed in $0.1 \mathrm{M}$ PB and incubated for $48 \mathrm{~h}$ in 1:200 of a rabbit polyclonal antibody directed against COX-2 (Yamagata et al., 1993) diluted in 0.1 M PB containing $0.3 \%$ Triton X-100 at 4 _C. The slices were then rinsed in 0.1 M PB and incubated overnight in secondary antibody conjugated with Alexa Fluor 488 at a dilution of 1:200 in $0.1 \mathrm{M}$ PB containing $0.3 \%$ Triton X-100. Finally, the slices were rinsed in 0.1 M PB, mounted on gelatin-coated glass slides and coverslipped in a $0.1 \mathrm{M}$ PB-glycerine mixture. The specificity of COX-2-immunoreactivity (-ir) was evaluated by omitting the primary antibody. The slices were examined with a confocal laser scanning microscope (Leica Microsystems Heidelberg, Mannheim, Germany) using 10_or 40_objective lens. Optical sections were scanned through the thickness of each slice, and single $1 \mathrm{~mm}$ thick optical sections at the same predetermined z-axis were collected for the analysis of COX-2-ir intensity. A method for measuring immunofluorescence intensity from blindcoded confocal images is detailed in Cammalleri et al. (2006), adapted from Gazzaley et al. (1997, 1996a,b). The software package KS-300 (Carl Zeiss Vision, München-Hallbergmoos, Germany) was used to determine the average pixel intensity (grey scale) of single fields in the stratum pyramidale of CA1 and CA3 regions, and in the granular layer of the dentate gyrus. Within each field, the contribution of unlabelled portions was removed, normalizing the data to the background fluorescence. Mean intensity values for each field were expressed as a percentage of the average fluorescence intensity of the corresponding field of hippocampal slices in basal conditions (aCSF). 


\subsection{PGE2 release assay}

PGE2 release was measured in hippocampal slices treated for $3 \mathrm{~h}$ in aCSF either alone or in combination with $0 \mathrm{Mg} 2 \mathrm{p} / 4-\mathrm{AP}$, without or with additional treatment with SRIF for $20 \mathrm{~min}$. In some experiments, PGE2 release was also measured in aCSF- or $0 \mathrm{Mg} 2 \mathrm{p} / 4-\mathrm{AP}$-treated slices in the presence of increasing concentrations of the COX-2 inhibitor NS-398 which was applied $2 \mathrm{~h}$ before the end of the incubation in either aCSF or $0 \mathrm{Mg} 2 \mathrm{p} / 4-\mathrm{AP}$. For each experimental condition, samples including 4 slices from different animals were collected and were centrifuged at $2000_{\text {_ }} \mathrm{g}$ for $5 \mathrm{~min}$. After centrifugation, the clear incubation medium ( $3 \mathrm{ml}$ for each sample) was used for measurements of PGE2 release according to previous studies in the rat epileptic hippocampus (Ajmone-Cat et al., 2006). In particular, PGE2 levels were detected using the high sensitivity colorimetric enzyme immunoassays (EIA) kit (Cayman Chemical, Inalco, Milano, Italy) according to the manufacturer's instructions. All measurements were run in triplicate for each sample. PGE2 concentration was determined spectrophotometrically by Victor3v microplate reader (PerkinElmer, Norwalk, CT, USA). Data were expressed as pg of PGE2 in the medium/ mg of the respective wet tissue. NS-398 inhibition of PGE2 release in aCSF-treated slices and in $0 \mathrm{Mg} 2 \mathrm{p} / 4$ AP-treated slices was calculated as a percentage of the basal or of the $0 \mathrm{Mg} 2 \mathrm{p} / 4-\mathrm{AP}$-induced PGE2 release, respectively.

\subsection{Electrophysiology}

Using published protocols (Cammalleri et al., 2004, 2006; Cervia et al., 2005a), at the end of the incubation in $0 \mathrm{Mg} 2 \mathrm{p} / 4-\mathrm{AP}$ hippocampal slices were transferred to an interface recording chamber containing fresh $0 \mathrm{Mg} 2 \mathrm{p}$ / 4-AP either in the absence and in the presence of NS-398 or meloxicam without or with SRIF. SRIF and NS-398 were also applied sequentially during the recording. Extracellular recordings of hippocampal discharge were performed from the stratum pyramidale of the CA1 region by using 2e5 MU microelectrodes filled with aCSF. Epileptiform bursts induced by $0 \mathrm{Mg} 2 \mathrm{p} / 4-\mathrm{AP}$ were amplified with an Axoclamp-2B amplifier (Axon Instruments, Foster City, CA, USA), filtered (DC $3 \mathrm{e} 10 \mathrm{kHz}$ ) and displayed on an oscilloscope. Signals were recorded for $20 \mathrm{~min}$. The interval between SRIF application and the recording of an observable effect was $6 \mathrm{e} 8 \mathrm{~min}$. All traces were analysed using the LabView software package (National Instruments, Austin, TX, USA). The data represent the mean discharge frequency (burst frequency/min) over the recording period. Inhibition of burst frequency was calculated as a percentage of the burst frequency in the presence of $0 \mathrm{Mg} 2 \mathrm{p} / 4-\mathrm{AP}$. 


\subsection{Data analysis}

Upon verification of normal distribution, statistical significance of data was evaluated using ANOVA followed by multiple comparison Bonferroni's posttest. The GraphPad Prism software package (Graph Software, San Diego, CA, USA) was used. Differences with $p<0.05$ were considered significant. Emax (maximum percentage effect) and IC50 (the concentration producing half the maximum inhibitory effect) were determined by non-linear regression curve analysis of the concentration-effect responses using GraphPad Prism. The results were expressed as means _ SEM of the indicated $n$ values.

\subsection{Chemicals}

SRIF was purchased from Bachem (Bubendorf, Switzerland). Primer pairs for COX-2 and cyclophilin B were purchased from Eurobio (Les Ulis, France). The rabbit polyclonal antibody directed against COX-2 was purchased from Chemicon (Temecula, CA, USA). Secondary antibody conjugated with Alexa Fluor 488 was purchased from Molecular Probes (Eugene, OR, USA). Where not specified, chemicals and reagents were obtained from Sigma-Aldrich (St. Louis, MO, USA).

\section{Results}

3.1. SRIF affects the increase in COX-2 expression induced by epileptiform bursting COX-2 expression was measured in aCSF-treated (basal condition) as well as in $0 \mathrm{Mg} 2 \mathrm{p} / 4-\mathrm{AP}$ treated slices (an experimental model of epileptiform bursting activity) both in the absence and in the presence of SRIF (20 min treatment). SRIF was used at $1 \mathrm{mM}$, a concentration giving maximal receptor occupancy in our system (Cammalleri et al., 2004, 2006; Cervia et al., 2005a), that was also used in previous studies on the effects of SRIF compounds in the rodent hippocampus (Boehm and Betz, 1997; Cammalleri et al., 2004, 2006; Moneta et al., 2002; Schweitzer et al., 1998; Tallent and Siggins, 1997, 1999). By means of RT-PCR, we found that $0 \mathrm{Mg} 2 \mathrm{p} / 4-\mathrm{AP}$ treatment increased COX-2 mRNA levels by 27 _ $3.4 \%$ (with respect to aCSF-treated slices) (Fig. 1). In the presence of SRIF, this increase was abolished. As shown in the confocal images of Fig. 2A, slices of the mouse hippocampus slices treated with aCSF, revealed constitutive COX-2 protein expression in many areas of this brain region, consistent with previous reports of mice and rats (Kawaguchi et al., 2005; Takemiya et al., 2003; Tu and Bazan, 2003; Voutsinos-Porche et al., 2004). In particular, prominent staining was in the pyramidal layer of all hippocampal areas as well as in the granular layer of the dentate gyrus. Higher magnifications (insets of Fig. 2A) revealed immunolabeling of pyramidal cell somata, of their dendritic fields in the stratum radiatum, of granular cell somata and of scattered 
cells located in the sub-pyramidal layer of the stratum oriens and in the subgranular layer of the stratum moleculare. After $0 \mathrm{Mg} 2 \mathrm{p} / 4-\mathrm{AP}$ treatment, COX-2-ir increased significantly when compared to basal conditions and this increase was reduced significantly by SRIF (Fig. 2B). In particular, as shown in Fig. 2C, COX-2- ir significantly increased in the pyramidal layers of CA1 $\left(17 \_2 \%\right)$ and CA3 $\left(24 \_3 \%\right)$ and in the granular layer of dentate gyrus $\left(37 \_3 \%\right)$, while SRIF completely restored COX-2-ir in CA1/CA3 regions and partially in the dentate gyrus.

\subsection{SRIF affects the increase in PGE2 release induced by epileptiform bursting}

EIA measurements of PGE2 release in mouse hippocampal slices revealed that $0 \mathrm{Mg} 2 \mathrm{p} / 4-\mathrm{AP}$ treatment increased the release of PGE2 by 26 _ $4.5 \%$ (with respect to aCSF-treated slices) (Fig. 3). After the application of $1 \mathrm{mM}$ SRIF for $20 \mathrm{~min}$, this increase was no longer observed.

\subsection{Inhibition of COX-2/PGE2 affects epileptiform bursting}

In agreement with previous papers (Chen and Bazan, 2005a; Chen et al., 2002; Sang et al., 2005; Takemiya et al., 2006), the selective COX-2 inhibitor NS-398 (Vane et al., 1998) was used in mouse hippocampal slices treated with $0 \mathrm{Mg} 2 \mathrm{p} / 4$-AP. According to Chen and Bazan (2005a), the slices were pretreated with NS-398 for at least $2 \mathrm{~h}$ to allow the inhibition of PGE2 formation during the time course of the experiment. As shown in Fig. 4A, NS-398 produced a concentrationdependent inhibition of $0 \mathrm{Mg} 2 \mathrm{p} / 4-\mathrm{AP}$-stimulated PGE2 release with an IC50 of $7.05 \mathrm{mM}$ and an Emax of $85 \%$. The effects of COX-2 inhibition on PGE2 formation in slices treated with aCSF were also examined (Fig. 4B). In these conditions, an inhibitory effect of NS-398 on PGE2 release (24 $4.1 \%)$ was detected only at the highest concentration tested $(50 \mathrm{mM})$.

To determine whether COX-2 participates in epileptiform bursting, NS-398 effects on hippocampal discharge extracellularly recorded from slices treated with $0 \mathrm{Mg} 2 \mathrm{p} / 4-\mathrm{AP}$ were also investigated (Figs. 5A,B). As expected, the frequency (29.7_ 0.2/min) and the duration (150e200 msec) of the bursting were consistent with previous data (Cammalleri et al., 2004, 2006; Cervia et al., 2005a). In addition, NS-398 ( $2 \mathrm{~h}$ pretreatment and continuously perfused in the recording bath) produced a concentration-dependent inhibition of $0 \mathrm{Mg} 2 \mathrm{p} / 4-\mathrm{AP}$-induced bursting frequency with an IC50 of $1.86 \mathrm{mM}$ and an Emax of 36\%. Another selective COX-2 inhibitor structurally different from NS398 was also used, i.e., meloxicam (Vane et al., 1998). Hippocampal slices were preincubated with increasing concentrations of meloxicam for $20 \mathrm{~min}$, according to previous studies (Slanina and Schweitzer, 2005). As shown in Figs. 5AeC, meloxicam (20 min pretreatment and continuously perfused in the recording bath) produced a concentration-dependent inhibition of $0 \mathrm{Mg} 2 \mathrm{p} / 4-\mathrm{AP}-$ induced bursting frequency with an IC50 of $9.24 \mathrm{mM}$ and an Emax of 34\%. 


\subsection{SRIF and NS-398 affect epileptiform bursting in a non-additive manner}

In another set of experiments (Fig. 6A), we found that the application of $1 \mathrm{mM} \mathrm{SRIF} \mathrm{(20} \mathrm{min)}$ reduced the $0 \mathrm{Mg} 2 \mathrm{p} / 4-\mathrm{APinduced}$ bursting frequency of mouse hippocampal slices by $31_{-} 1.7 \%$, in agreement with previous reports (Cammalleri et al., 2004, 2006; Cervia et al., 2005a). The effects of NS-398 either alone or in combination with SRIF on Mg2p/4-AP-induced bursting were also investigated. In agreement with the pharmacological parameters reported above, NS-398 was used at $10 \mathrm{mM}$, a concentration higher than the reported IC50 for COX-2, but lower than the IC50 for COX-1 (Vane et al., 1998). NS-398 (2 h pretreatment and continuously perfused in the recording bath) decreased the Mg2p/4-AP-induced bursting frequency by $36 \_0.7 \%$ and this inhibitory effect remained unchanged after the application of $1 \mathrm{mM}$ SRIF for $20 \mathrm{~min}$. NS- 398 was also applied after SRIF and superfused for $30 \mathrm{~min}$ in the recording bath. Results of these experiments demonstrated that sequential application of SRIF and NS-398 did not alter the inhibitory effect of SRIF alone. In order to validate this experimental setting, we demonstrated that NS-398 effects on Mg2p/4-APinduced bursting frequency obtained at 10 mMafter 30 min superfusion in the recording bath (39 $0.5 \%$ of inhibition) were similar to those achieved after $2 \mathrm{~h}$ pretreatment (Fig. 6B).

\subsection{PGE2 abolishes the inhibitory effect of SRIF on epileptiform bursting}

The involvement of PGE2 in the modulation of hippocampal bursting was further supported by results from experiments with application of exogenous PGE2. PGE2 was applied at $1 \mathrm{mM}$, a concentration which increases membrane excitability of rat hippocampal neurons (Chen and Bazan, 2005a). As shown in Fig. 7, the sequential application of PGE2 abolished the inhibitory effect of 1 mM SRIF (20 min) on epileptiform bursting.

\section{Discussion}

In the present study, we have examined whether the COX-2 pathway is functionally coupled to the SRIF inhibitory action on mouse hippocampal epileptiform bursting. COX enzymes are hemecontaining bis-oxygenases that catalyse the first committed reaction in metabolism of AA, whose metabolites (i.e., the PGs) affect a wide spectrum of activities in the nervous system, including epileptogenesis (for a review see Cole- Edwards and Bazan, 2005; Hewett et al., 2006; Phillis et al., 2006). Previous results have reported that, in the mouse and rat hippocampus, COX-2 and/or PGE2 are increased after seizures in different experimental models (Kawaguchi et al., 2005; Takemiya et al., 2003, 2006; Tu and Bazan, 2003). We demonstrate here that, in the mouse hippocampus, the expression of COX-2 (at both mRNA and protein level) and the endogenous release of PGE2 
increase in concomitance with epileptiform bursting (interictal-like activity) induced by $0 \mathrm{Mg} 2 \mathrm{p} / 4$ AP. In particular, quantitative evaluation of COX-2 immunofluorescent labeling has revealed that COX-2 protein increases in the pyramidal layers of CA1/CA3 and in the granular layer of the dentate gyrus. Accordingly, in a rat lithium-pilocarpine model of temporal lobe epilepsy, COX-2 protein has been recently shown to up-regulate in the whole hippocampus (Voutsinos-Porche et al., 2004). Similarly, COX-2 protein is up-regulated in CA3 and in the dentate gyrus of rats after kainate-induced limbic seizures (Kawaguchi et al., 2005). We have also observed that, in the mouse hippocampus, the COX inhibitor NS-398 has a slight effect on endogenous PGE2 release in control conditions while it markedly decreases endogenous PGE2 release induced by $0 \mathrm{Mg} 2 \mathrm{p} / 4-\mathrm{AP}$ with a potency 2.4-fold higher than the affinity value reported for the inhibition of COX-1 (Vane et al., 1998). These results indicate that PGE2 produced during epilepsy is mainly a results of COX-2 activity. That PGE2 is mainly synthesized by COX-2 has been previously demonstrated in the rodent hippocampus (Chen and Bazan, 2005a; Chen et al., 2002; Kawaguchi et al., 2005; Sang et al., 2005; Takemiya et al., 2006). Our additional finding that NS-398 drastically reduces epileptiform bursting with a potency 4.1-fold higher than the affinity value for the inhibition of PGE2 release suggests that, in our system, a relative small degree of COX-2/ PGE2 inhibition is required to obtain a significant inhibition of epileptiform bursting. Our data obtained with meloxicam, another selective COX-2 inhibitor structurally different from NS-398, further suggest the involvement of COX-2 in epileptiform bursting. As recently reviewed by Hewett et al. (2006), COX-2 inhibitors seem to differentially attenuate both hippocampal seizures and neurodegenerative changes which precede seizure development. In particular, the inhibition by NS-398 of PGE2 production in the rat hippocampus seizured with kainic acid has been shown to prevent neuronal death (Takemiya et al., 2006). In addition, meloxicam was demonstrated to decrease CA1 excitatory responses in rat hippocampal slices (Slanina and Schweitzer, 2005). On the other hand, it is noteworthy that the outcome of COX-2 inhibition in the epileptic model appears to be dependent, at least in part, on the treatment paradigm employed (Gobbo and O'Mara, 2004). Taken together, these data demonstrate that, in the mouse hippocampus, the COX-2/PGE2 pathway facilitates epileptiform bursting induced by $0 \mathrm{Mg} 2 \mathrm{p} / 4-\mathrm{AP}$ and is in line with the concept that $\mathrm{COX}-2$ inhibition may exert an antiepileptogenic role.

In the hippocampus, SRIF is present in distinct interneurons and acts in concert with gaminobutyric acid (GABA), the primary inhibitory neurotransmitter in the central nervous system (which has a central role in epilepsy), with which it is colocalized and sometimes co-released (Binaschi et al., 2003; Cossart et al., 2005; Jinno and Kosaka, 2004; Matyas et al., 2004). Interneurons are often classified according to neuropeptide content. Recent advances in 
understanding neuropeptide release and physiological actions suggest that the interneuronal system of neuropeptides is crucial for maintaining appropriate brain function under normal and pathophysiological conditions, including epilepsy (Baraban and Tallent, 2004). Among neuropeptides, SRIF is released in characteristic conditions of seizures (Binaschi et al., 2003; Vezzani and Hoyer, 1999). In addition, epileptic patients and experimental models of epilepsy display loss of SRIF neurons in the hippocampus (Buckmaster et al., 2002; Sun et al., 2007). Functionally, the effects of SRIF compounds on excitatory transmission are largely modulatory and include a powerful inhibition of excitation (and, sometimes, an increase of the inhibition) in selected regions of the hippocampus (Baraban and Tallent, 2004; Binaschi et al., 2003; Tallent and Siggins, 1999; Vezzani and Hoyer, 1999). There are recent studies in mouse hilar neurons (often among the first lost in hippocampal epilepsy) which indicate that SRIF hyperpolarizes and reduces the spike frequency of these cells (Fu and van den Pol, 2007). In the mouse hippocampus, SRIF inhibition of epileptiform bursting induced by $0 \mathrm{Mg} 2 \mathrm{p} / 4-\mathrm{AP}$ has been shown in CA1 and CA3 regions (Cammalleri et al., 2004, 2006; Cervia et al., 2005a), but information on signalling mediating SRIF actions is still limited (Cervia and Bagnoli, 2007). Here, we present data indicating that SRIF exerts an anti-epileptic role in a functional model of hippocampal bursting by negative coupling to the COX-2/PGE2 pathway. Among the indirect evidence, we found that, in the mouse hippocampus treated with $0 \mathrm{Mg} 2 \mathrm{p} / 4-\mathrm{AP}, \mathrm{SRIF}$ counteracts the increase of both COX-2 expression and PGE2 release which occurs in concomitance with epileptiform bursting. In addition, SRIF and NS-398 comparably reduce epileptiform bursting. Moreover, PGE2 abolished the inhibitory effect of SRIF on epileptiform bursting, thus demonstrating that PGE2 takes a serious part in COX- 2 products. The finding that the effects of SRIF and NS-398 (SRIF applied after NS-398 and viceversa) are non-additive suggests that they converge upon signalling mechanisms involving the inhibition of COX-2/PGE2, thus providing a direct link (through a pharmacological approach) between COX-2/ PGE2 and SRIF. In addition, our data are not entirely consistent with the possibility that SRIF may indirectly reduce COX-2/PGE2 as a consequence of the SRIF-induced decrease of neuronal activity: if that was the case, a further reduction of epileptiform bursting should be seen following SRIF application in the presence of NS-398. Although we cannot exclude that such basic effect may take some part in the SRIF-induced modulation of COX-2/PGE2, we favour the possibility that, in the mouse hippocampus, SRIF binding to its G-protein coupled receptors leads to inhibition of PGE2 through both PLA2 inhibition and downregulation of COX-2 expression. In this respect, SRIF negative coupling to PLA2/AA pathway has been demonstrated in the rat diaphragm (Arias-Diaz et al., 1997), and in rat GC cells (Cervia et al., 2002). As previously reported in different experimental models (Boehm and Betz, 1997; Schweitzer et al., 1998; Tallent 
and Siggins, 1997, 1999), SRIF actions in the hippocampus may involve the modulation of glutamatergic currents, (i.e., the pharmacologically isolated AMPA and NMDA receptor-mediated excitatory synaptic currents) andGABAergic currents. SRIF-induced modulation of different $\mathrm{Kp}$ and $\mathrm{Ca} 2 \mathrm{p}$ currents may also occur. In particular, previous experiments performed on postsynaptic potentials of CA1 pyramidal cells of the mouse hippocampus treated with $0 \mathrm{Mg} 2 \mathrm{p} / 4-\mathrm{AP}$ have demonstrated that SRIF not only decreases neuronal responsiveness to glutamate (AMPAandNMDAcurrents) but also increases inhibitory transmission (GABAA currents) (Cammalleri et al., 2006). These effects are paralleled by the SRIF-mediated inhibition of adenylyl cyclase activity (Cammalleri et al., 2004, 2006), although a direct involvement of cAMP pathway on SRIF actions needs to be further demonstrated. A role of PLA2/AA/COXs/PGs pathway in the modulation ofAMPA,NMDAand/orGABAreceptor activity is well established in the hippocampus (Brady et al., 2006; Menard et al., 2005a,b; Pepicelli et al., 2005; Schwartz- Bloom and Sah, 2001; Shen et al., 2007). Thus, we can speculate that, among the different coupling mechanisms which may mediate SRIF modulation of AMPA, NMDA and/or GABAA currents, an important role may be ascribed to SRIF negative coupling to the COX-2/PGE2 pathway. This is also in line with recent findings in the rat hippocampus, demonstrating that COX-2 mediates the decrease of excitatory transmission exerted by neuropeptides other than SRIF such as cannabinoids (Slanina and Schweitzer, 2005). In this respect, that cannabinoids can effectively block status epilepticus has been recently demonstrated in rat hippocampal neuronal cultures (Deshpande et al., 2007).

\section{Remarks}

In conclusion, in this paper we have identified a key set of signalling events that underlie anticonvulsant effects of SRIF in a mouse model of hippocampal bursting. In particular, our results not only confirm that the COX-2/PGE2 pathway is upregulated by seizures, but also demonstrate for the first time that the SRIF-induced inhibition of epileptiform bursting involves a downregulation of the COX-2/PGE2 pathway. Generally, PGs are a family of structurally related lipid mediators playing critical roles in the initiation and modulation of inflammation. In this respect, a SRIF role as an anti-inflammatory agent has emerged recently (for ref. see Armani et al., 2007; Szokoloczi et al., 2005), and it is noteworthy that some anti-inflammatory treatments reduce epileptic activity in different animal models of epilepsy and, in some instances, in clinical cases of epilepsy, thus opening new perspectives for the pharmacological treatment of seizures (Phillis et al., 2006; Vezzani and Granata, 2005). Indeed, available therapy for epilepsy is only symptomatic and often ineffective. Therefore, a great deal of effort has been devoted to identifying new antieplectic drugs, with mechanisms of action different from those currently in use (Stefan and Feuerstein, 2007; 
Stepien et al., 2005; Wuttke and Lerche, 2006). Thus, elucidation of SRIF signalling in nervous system diseases, including epilepsy, warrants further study not only to identify alternative intervention points for the modulation of SRIF function, but also to exploit new chemical space for drug-like molecules.

\section{Acknowledgements}

This work has been supported by the Italian Board of Education (MIUR Internationalization, Art. 123). We wish to thank Dr. A. Gazzano and G. Bertolini (University of Pisa, Italy) for assistance with mouse colonies.

\section{References}

Ajmone-Cat, M.A., Iosif, R.E., Ekdahl, C.T., Kokaia, Z., Minghetti, L., Lindvall, O., 2006.

Prostaglandin E2 and BDNF levels in rat hippocampus are negatively correlated with status epilepticus severity: no impact on survival of seizure-generated neurons. Neurobiol. Dis. 23, $23 \mathrm{e} 35$. Arias-Diaz, J., Vara, E., Torres-Melero, J., Garcia, C., Hernandez, J., Balibrea, J.L., 1997. Local production of oxygen free radicals and nitric oxide in rat diaphragm during sepsis: effects of pentoxifylline and somatostatin. Eur. J. Surg. 163, 619e625.

Armani, C., Catalani, E., Balbarini, A., Bagnoli, P., Cervia, D., 2007. Expression, pharmacology, and functional role of somatostatin receptor subtypes 1 and 2 in human macrophages. J. Leukoc. Biol. 81, 845e855.

Avoli, M., 2001. Do interictal discharges promote or control seizures? Experimental evidence from an in vitro model of epileptiform discharge. Epilepsia 42 (Suppl. 3), $2 \mathrm{e} 4$.

Baraban, S.C., Tallent, M.K., 2004. Interneuron diversity series: interneuronal neuropeptidesdendogenous regulators of neuronal excitability. Trends Neurosci. 27, 135e142.

Binaschi, A., Bregola, G., Simonato, M., 2003. On the role of somatostatin in seizure control: clues from the hippocampus. Rev. Neurosci 14, 85e301.

Boehm, S., Betz, H., 1997. Somatostatin inhibits excitatory transmission at rat hippocampal synapses via presynaptic receptors. J. Neurosci. 17, 4066e4075.

Brady, K.M., Texel, S.J., Kishimoto, K., Koehler, R.C., Sapirstein, A., 2006. Cytosolic phospholipase A alpha modulates NMDA neurotoxicity in mouse hippocampal cultures. Eur. J. Neurosci. 24, 3381e3386.

Buckmaster, P.S., Otero-Corchon, V., Rubinstein, M., Low, M.J., 2002. Heightened seizure severity in somatostatin knockout mice. Epilepsy Res. 48, $43 \mathrm{e} 56$. 
Cammalleri, M., Cervia, D., Langenegger, D., Liu, Y., Dal Monte, M., Hoyer, D., Bagnoli, P., 2004. Somatostatin receptors differentially affect spontaneous epileptiform activity in mouse hippocampal slices. Eur. J. Neurosci. 20, 2711e2721.

Cammalleri, M., Cervia, D., Dal Monte, M., Martini, D., Langenegger, D., Fehlmann, D., Feuerbach, D., Pavan, B., Hoyer, D., Bagnoli, P., 2006. Compensatory changes in the hippocampus of somatostatin knockout mice: upregulation of somatostatin receptor 2 and its function in the control of bursting activity and synaptic transmission. Eur. J. Neurosci. 23, 2404e2422.

Cervia, D., Bagnoli, P., 2007. An update on somatostatin receptor signalling in native systems and new insights on their pathophysiology. Pharmacol. Ther. 116, 322e341.

Cervia, D., Fiorini, S., Pavan, B., Biondi, C., Bagnoli, P., 2002. Somatostatin (SRIF) modulates distinct signaling pathways in rat pituitary tumor cells; negative coupling of SRIF receptor subtypes 1 and 2 to arachidonic acid release. Naunyn Schmiedebergs Arch. Pharmacol. 365, 200e209.

Cervia, D., Langenegger, D., Schuepbach, E., Cammalleri, M., Schoeffter, P., Schmid, H.A., Bagnoli, P., Hoyer, D., 2005a. Binding and functional properties of the novel somatostatin analogue KE 108 at native mouse somatostatin receptors. Neuropharmacology 48, 881e893.

Cervia, D., Nunn, C., Bagnoli, P., 2005b. Multiple signalling transduction mechanisms differentially coupled to somatostatin receptor subtypes: a current view. Curr. Enzyme Inhibition 1, $265 \mathrm{e} 279$.

Chen, C., Bazan, N.G., 2005a. Endogenous PGE2 regulates membrane excitability and synaptic transmission in hippocampal CA1 pyramidal neurons. J. Neurophysiol. 93, 929e941.

Chen, C., Bazan, N.G., 2005b. Lipid signaling: sleep, synaptic plasticity, and neuroprotection. Prostaglandins Other Lipid Mediat. 77, $65 \mathrm{e} 76$.

Chen, C., Magee, J.C., Bazan, N.G., 2002. Cyclooxygenase-2 regulates prostaglandin E2 signaling in hippocampal long-term synaptic plasticity. J. Neurophysiol. 87, 2851e2857.

Cole-Edwards, K.K., Bazan, N.G., 2005. Lipid signaling in experimental epilepsy. Neurochem. Res. 30, 847e853.

Cossart, R., Bernard, C., Ben-Ari, Y., 2005. Multiple facets of GABAergic neurons and synapses: multiple fates of GABA signalling in epilepsies. Trends Neurosci. 28, 108e115.

Deshpande, L.S., Blair, R.E., Ziobro, J.M., Sombati, S., Martin, B.R., DeLorenzo, R.J., 2007. Endocannabinoids block status epilepticus in cultured hippocampal neurons. Eur. J. Pharmacol. $558,52 \mathrm{e} 59$.

Fu, L.Y., van den Pol, A.N., 2007. GABA excitation in mouse hilar neuropeptide Y neurons. J. Physiol. 579, 445e464. 
Gazzaley, A.H., Siegel, S.J., Kordower, J.H., Mufson, E.J., Morrison, J.H., 1996a. Circuit-specific alterations of N-methyl-D-aspartate receptor subunit 1 in the dentate gyrus of aged monkeys. Proc. Natl. Acad. Sci. USA 93, 3121e3125.

Gazzaley, A.H., Weiland, N.G., McEwen, B.S., Morrison, J.H., 1996b. Differential regulation of NMDAR1 mRNA and protein by estradiol in the rat hippocampus. J. Neurosci. 16, 6830e6838. Gazzaley, A.H., Benson, D.L., Huntley, G.W., Morrison, J.H., 1997. Differential subcellular regulation of NMDAR1 protein and mRNA in dendrites of dentate gyrus granule cells after perforant path transection. J. Neurosci. 17, $2006 \mathrm{e} 2017$.

Gobbo, O.L., O’Mara, S.M., 2004. Post-treatment, but not pre-treatment, with the selective cyclooxygenase-2 inhibitor celecoxib markedly enhances functional recovery from kainic acidinduced neurodegeneration. Neuroscience 125, $317 \mathrm{e} 327$.

Hewett, S.J., Bell, S.C., Hewett, J.A., 2006. Contributions of cyclooxygenase- 2 to neuroplasticity and neuropathology of the central nervous system. Pharmacol. Ther. 112, 335e 357 .

Jinno, S., Kosaka, T., 2004. Patterns of colocalization of neuronal nitric oxide synthase and somatostatin-like immunoreactivity in the mouse hippocampus: quantitative analysis with optical disector. Neuroscience 124, 797e808.

Kawaguchi, K., Hickey, R.W., Rose, M.E., Zhu, L., Chen, J., Graham, S.H., 2005.

Cyclooxygenase- 2 expression is induced in rat brain after kainate-induced seizures and promotes neuronal death in CA3 hippocampus. Brain Res. 1050, 130e137.

Matyas, F., Freund, T.F., Gulyas, A.I., 2004. Immunocytochemically defined interneuron populations in the hippocampus of mouse strains used in transgenic technology. Hippocampus 14, $460 \mathrm{e} 481$.

McNamara, J.O., Huang, Y.Z., Leonard, A.S., 2006. Molecular signaling mechanisms underlying epileptogenesis. Sci. STKE 2006, re12.

Menard, C., Patenaude, C., Massicotte, G., 2005a. Phosphorylation of AMPA receptor subunits is differentially regulated by phospholipase A2 inhibitors. Neurosci. Lett. 389, 51e56.

Menard, C., Valastro, B., Martel, M.A., Chartier, E., Marineau, A., Baudry, M., Massicotte, G., 2005b. AMPA receptor phosphorylation is selectively regulated by constitutive phospholipase A(2) and 5-lipoxygenase activities. Hippocampus 15, 370e380.

Moneta, D., Richichi, C., Aliprandi, M., Dournaud, P., Dutar, P., Billard, J.M., Carlo, A.S., Viollet, C., Hannon, J.P., Fehlmann, D., Nunn, C., Hoyer, D., Epelbaum, J., Vezzani, A., 2002.

Somatostatin receptor subtypes 2 and 4 affect seizure susceptibility and hippocampal excitatory neurotransmission in mice. Eur. J. Neurosci. 16, 843e849. 
Pepicelli, O., Fedele, E., Berardi, M., Raiteri, M., Levi, G., Greco, A., Ajmone- Cat, M.A., Minghetti, L., 2005. Cyclo-oxygenase-1 and -2 differently contribute to prostaglandin E2 synthesis and lipid peroxidation after in vivo activation of N-methyl-D-aspartate receptors in rat hippocampus. J. Neurochem. 93, 1561e1567.

Phillis, J.W., Horrocks, L.A., Farooqui, A.A., 2006. Cyclooxygenases, lipoxygenases, and epoxygenases in CNS: their role and involvement in neurological disorders. Brain Res. Rev. 52, $201 \mathrm{e} 243$.

Sang,N., Zhang, J.,Marcheselli,V.,Bazan,N.G.,Chen, C., 2005. Postsynaptically synthesized prostaglandin E2 (PGE2) modulates hippocampal synaptic transmission via a presynaptic PGE2 EP2 receptor. J. Neurosci. 25, 9858e9870.

Sanna, P.P., Berton, F., Cammalleri, M., Tallent, M.K., Siggins, G.R., Bloom, F.E., Francesconi, W., 2000. A role for Src kinase in spontaneous epileptiform activity in the CA3 region of the hippocampus. Proc. Natl. Acad. Sci. USA 97, 8653e8657.

Schwartz-Bloom, R.D., Sah, R., 2001. gamma-Aminobutyric acid(A) neurotransmission and cerebral ischemia. J. Neurochem. 77, 353e371.

Schweitzer, P., Madamba, S.G., Siggins, G.R., 1998. Somatostatin increases a voltage-insensitive Kp conductance in rat CA1 hippocampal neurons. J. Neurophysiol. 79, 1230e1238.

Shen, F., Bai, A.P., Guo, Z.R., Cheng, G.F., 2002. Inhibitory effect of 3,4-diaryl- 3-pyrrolin-2-one derivatives on cyclooxygenase 1 and 2 in murine peritoneal macrophages. Acta Pharmacol. Sin. 23, $762 \mathrm{e} 768$.

Shen, Y., Kishimoto, K., Linden, D.J., Sapirstein, A., 2007. Cytosolic phospholipase $\mathrm{A}(2)$ alpha mediates electrophysiologic responses of hippocampal pyramidal neurons to neurotoxic NMDA treatment. Proc. Natl. Acad. Sci. USA 104, 6078e6083.

Slanina, K.A., Schweitzer, P., 2005. Inhibition of cyclooxygenase-2 elicits a CB1-mediated decrease of excitatory transmission in rat CA1 hippocampus. Neuropharmacology 49, 653e659. Stefan, H., Feuerstein, T.J., 2007. Novel anticonvulsant drugs. Pharmacol. Ther. 113, 165e183. Stepien, K., Tomaszewski, M., Czuczwar, S.J., 2005. Profile of anticonvulsant activity and neuroprotective effects of novel and potential antiepileptic drugsdan update. Pharmacol. Rep. 57, $719 \mathrm{e} 733$.

Sun, C., Mtchedlishvili, Z., Bertram, E.H., Erisir, A., Kapur, J., 2007. Selective loss of dentate hilar interneurons contributes to reduced synaptic inhibition of granule cells in an electrical stimulationbased animal model of temporal lobe epilepsy. J. Comp. Neurol. 500, 876e893. 
Szokoloczi, O., Schwab, R., Petak, I., Orfi, L., Pap, A., Eberle, A.N., Szuts, T., Keril, G., 2005. TT232, a novel signal transduction inhibitory compound in the therapy of cancer and inflammatory diseases. J. Recept. Signal Transduct. Res. 25, 217e235.

Takemiya, T., Suzuki, K., Sugiura, H., Yasuda, S., Yamagata, K., Kawakami, Y., Maru, E., 2003. Inducible brain COX-2 facilitates the recurrence of hippocampal seizures in mouse rapid kindling. Prostaglandins Other Lipid Mediat. 71, $205 \mathrm{e} 216$.

Takemiya, T., Maehara, M., Matsumura, K., Yasuda, S., Sugiura, H., Yamagata, K., 2006.

Prostaglandin E2 produced by late induced COX-2 stimulates hippocampal neuron loss after seizure in the CA3 region. Neurosci. Res. 56, $103 \mathrm{e} 110$.

Tallent, M.K., Siggins, G.R., 1997. Somatostatin depresses excitatory but not inhibitory neurotransmission in rat CA1 hippocampus. J. Neurophysiol. 78, 3008e3018.

Tallent, M.K., Siggins, G.R., 1999. Somatostatin acts in CA1 and CA3 to reduce hippocampal epileptiform activity. J. Neurophysiol. 81, 1626e1635.

Tu, B., Bazan, N.G., 2003. Hippocampal kindling epileptogenesis upregulates neuronal cyclooxygenase-2 expression in neocortex. Exp. Neurol. 179, 167e175.

Vane, J.R., Bakhle, Y.S., Botting, R.M., 1998. Cyclooxygenases 1 and 2. Annu. Rev. Pharmacol. Toxicol. 38, 97e120.

Vezzani, A., Granata, T., 2005. Brain inflammation in epilepsy: experimental and clinical evidence. Epilepsia 46, 1724e1743.

Vezzani, A., Hoyer, D., 1999. Brain somatostatin: a candidate inhibitory role in seizures and epileptogenesis. Eur. J. Neurosci. 11, 3767e3776.

Voutsinos-Porche, B., Koning, E., Kaplan, H., Ferrandon, A., Guenounou, M., Nehlig, A., Motte, J., 2004. Temporal patterns of the cerebral inflammatory response in the rat lithium-pilocarpine model of temporal lobe epilepsy. Neurobiol. Dis. 17, 385e402.

Weckbecker, G., Lewis, I., Albert, R., Schmid, H.A., Hoyer, D., Bruns, C., 2003. Opportunities in somatostatin research: biological, chemical and therapeutic aspects. Nat. Rev. Drug Discov. 2, $999 \mathrm{e} 1017$.

Wuttke, T.V., Lerche, H., 2006. Novel anticonvulsant drugs targeting voltagedependent ion channels. Expert Opin. Investig. Drugs 15, 1167e1177. Yamagata, K., Andreasson, K.I., Kaufmann, W.E., Barnes, C.A., Worley, P.F., 1993. Expression of a mitogen-inducible cyclooxygenase in brain neurons: regulation by synaptic activity and glucocorticoids. Neuron. 11, 371e386.

Figure Legends 
Fig. 1. Measurements of COX-2 mRNA in hippocampal slices treated with aCSF, $0 \mathrm{Mg} 2 \mathrm{p} / 4-\mathrm{AP}$ and $0 \mathrm{Mg} 2 \mathrm{p} / 4-\mathrm{AP}$ p1 mM SRIF. Representative RTPCR products corresponding to COX-2 or cyclophilin B (internal standard) are shown in the upper panel, whereas the semi-quantitative RTPCR analysis is in the lower panel. Each histogram represents the mean _ SEM (bars) of data from 6 independent experiments. ${ }^{*} \mathrm{p}<0.001$ vs aCSF (ANOVA followed by Bonferroni’s post-test).

Fig. 2. (A) Regional distribution of COX-2-ir in a hippocampal slice treated with aCSF. This lowmagnification image is a reconstruction of 7 confocal optical sections acquired with a 10_objective. Prominent COX-2 immunostaining was observed in the pyramidal layer (Pyr) of CA1-CA3 and in the granular layer (Gr) of the dentate gyrus. As shown in the insets (40_ objective), COX-2-ir could be detected in pyramidal cell dendrites in the stratum radiatum (Rad) as well as in scattered immunostained somata in the stratum oriens (Or) and in the stratum moleculare (Mol). Scale bars: $300 \mathrm{~mm}$ for the low magnification image, $40 \mathrm{~mm}$ for the images in the insets. (B) Representative images of the regional distribution of COX-2-ir in hippocampal slices treated with $0 \mathrm{Mg} 2 \mathrm{p} / 4-\mathrm{AP}$ and $0 \mathrm{Mg} 2 \mathrm{p} / 4-\mathrm{AP} \mathrm{p} 1 \mathrm{mM}$ SRIF. Similar to the image in the upper panel, these images are reconstructions from multiple confocal optical sections. Scale bar: $300 \mathrm{~mm}$. (C) Relative fluorescence intensity of COX-2-ir in distinct regions of hippocampal slices under the different experimental conditions. Each histogram represents the mean _ SEM (bars) of data from 6 measurements in different fields of 3 independent experiments. ${ }^{*} \mathrm{p}<0.01 \mathrm{vs}$ aCSF and \#p $<0.05$ vs the respective $0 \mathrm{Mg} 2 \mathrm{p} / 4-\mathrm{AP}$ (ANOVA followed by Bonferroni's post-test).

Fig. 3. Measurements of PGE2 release in hippocampal slices treated with aCSF, $0 \mathrm{Mg} 2 \mathrm{p} / 4-\mathrm{AP}$ and $0 \mathrm{Mg} 2 \mathrm{p} / 4-\mathrm{AP}$ p1 mM SRIF. Each histogram represents the mean _ SEM (bars) of data from 4 independent experiments run in triplicate. * ${ }^{*}<0.001$ vs aCSF (ANOVA followed by Bonferroni's posttest).

Fig. 4. Measurements of PGE2 release in hippocampal slices treated with $0 \mathrm{Mg} 2 \mathrm{p} / 4-\mathrm{AP}(\mathrm{A})$ or in aCSF (B) in the presence of increasing concentrations of the COX-2 inhibitor NS-398. The data points represent the mean _ SEM of data from 4 independent experiments run in triplicate.

Fig. 5. (A) Measurements of epileptiform bursting in hippocampal slices treated with $0 \mathrm{Mg} 2 \mathrm{p} / 4-\mathrm{AP}$ in the presence of increasing concentrations of the COX-2 inhibitors NS-398 or meloxicam. The 
data points represent the mean _ SEM of data from 4 independent experiments. (B, C)

Representative traces depicting electrophysiological recordings of epileptiform bursting.

Fig. 6. (A) Measurements of epileptiform bursting in hippocampal slices treated with $0 \mathrm{Mg} 2 \mathrm{p} / 4-\mathrm{AP}$ in the absence or in the presence of $1 \mathrm{mM} \mathrm{SRIF}$ and/or $10 \mathrm{mM}$ NS-398. Each histogram represents the mean _ SEM (bars) of data from 6 independent experiments. *p $<0.001$ vs 0 Mg2p/4-AP (ANOVA followed by Bonferroni’s post-test). Representative traces depicting electrophysiological recordings of epileptiform bursting are shown in the right panel. (B) Measurements of epileptiform bursting in hippocampal slices treated with $0 \mathrm{Mg} 2 \mathrm{p} / 4-\mathrm{AP}$ in the presence of $10 \mathrm{mM} \mathrm{NS}-398$ at increasing times of superfusion in the recording bath. Each histogram represents the mean _ SEM (bars) of data from 4 independent experiments. ${ }^{*} \mathrm{p}<0.001$ vs $0 \mathrm{Mg} 2 \mathrm{p} / 4-\mathrm{AP}$ and $\mathrm{xp}<0.01$ vs 20 min superfusion (ANOVA followed by Bonferroni's post-test). Representative traces depicting electrophysiological recordings of epileptiform bursting are shown in the right panel.

Fig. 7. Measurements of epileptiform bursting in hippocampal slices treated with $0 \mathrm{Mg} 2 \mathrm{p} / 4-\mathrm{AP}$ in the absence or in the presence of $1 \mathrm{mM}$ SRIF and $1 \mathrm{mM}$ PGE2. Each histogram represents the mean _ SEM (bars) of data from 4 independent experiments. *p < 0.001 vs 0 Mg2p/4-AP (ANOVA followed by Bonferroni's posttest). Representative traces depicting electrophysiological recordings of epileptiform bursting are shown in the right panel. 


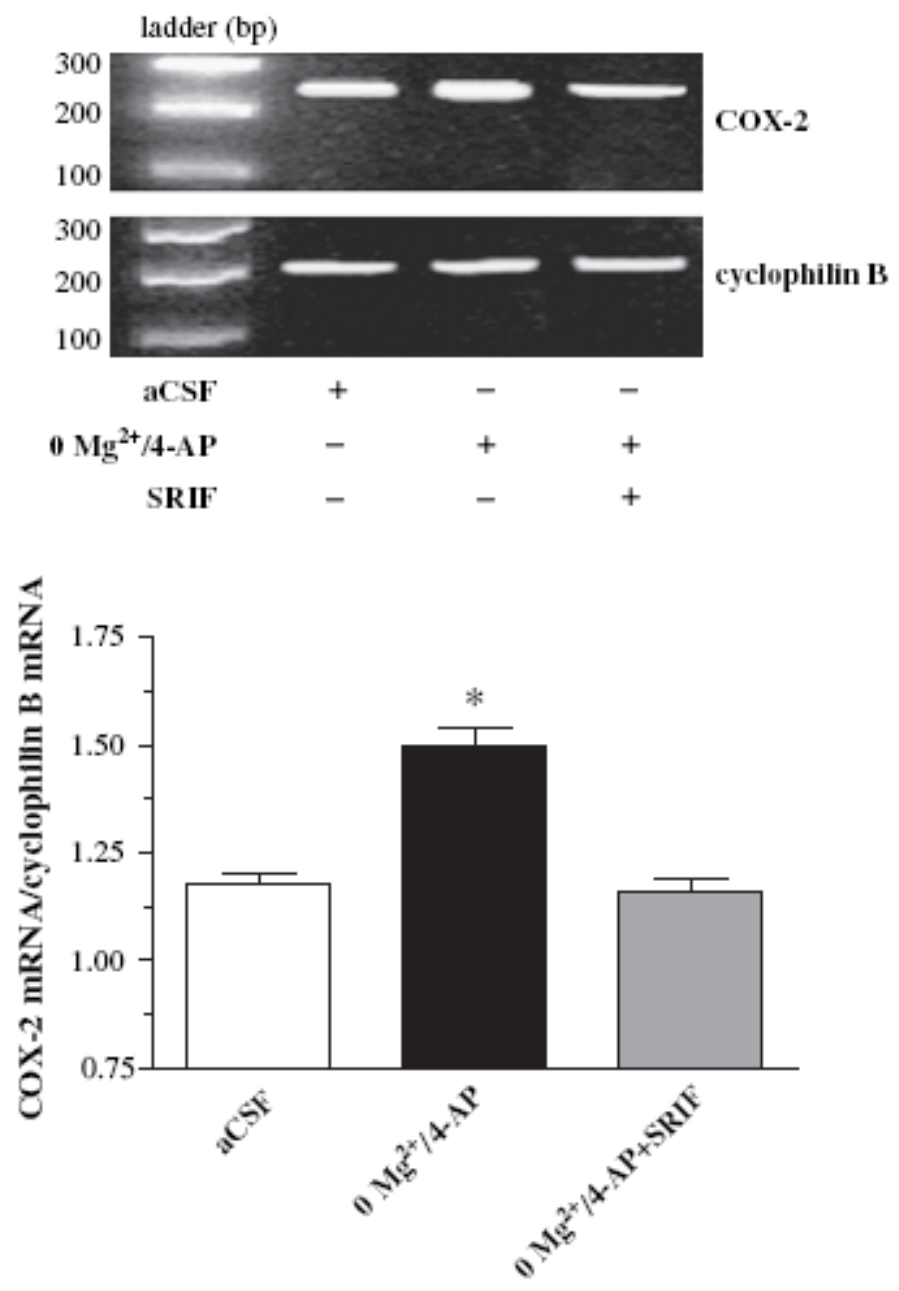

Fig.1 


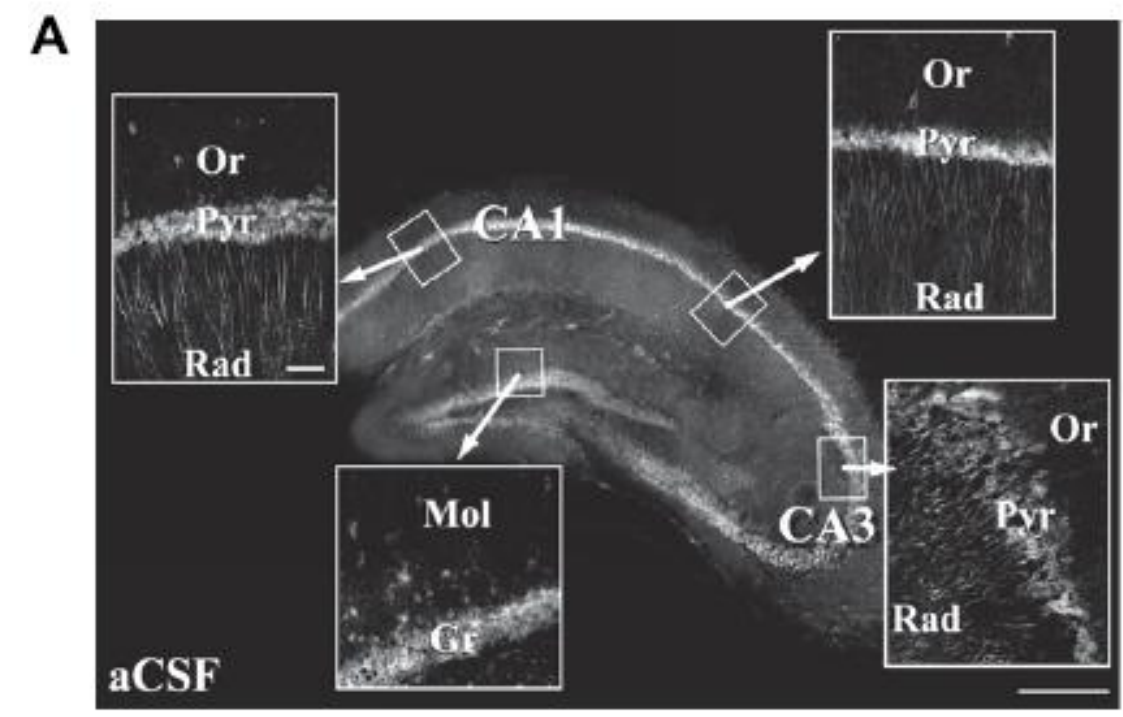

B
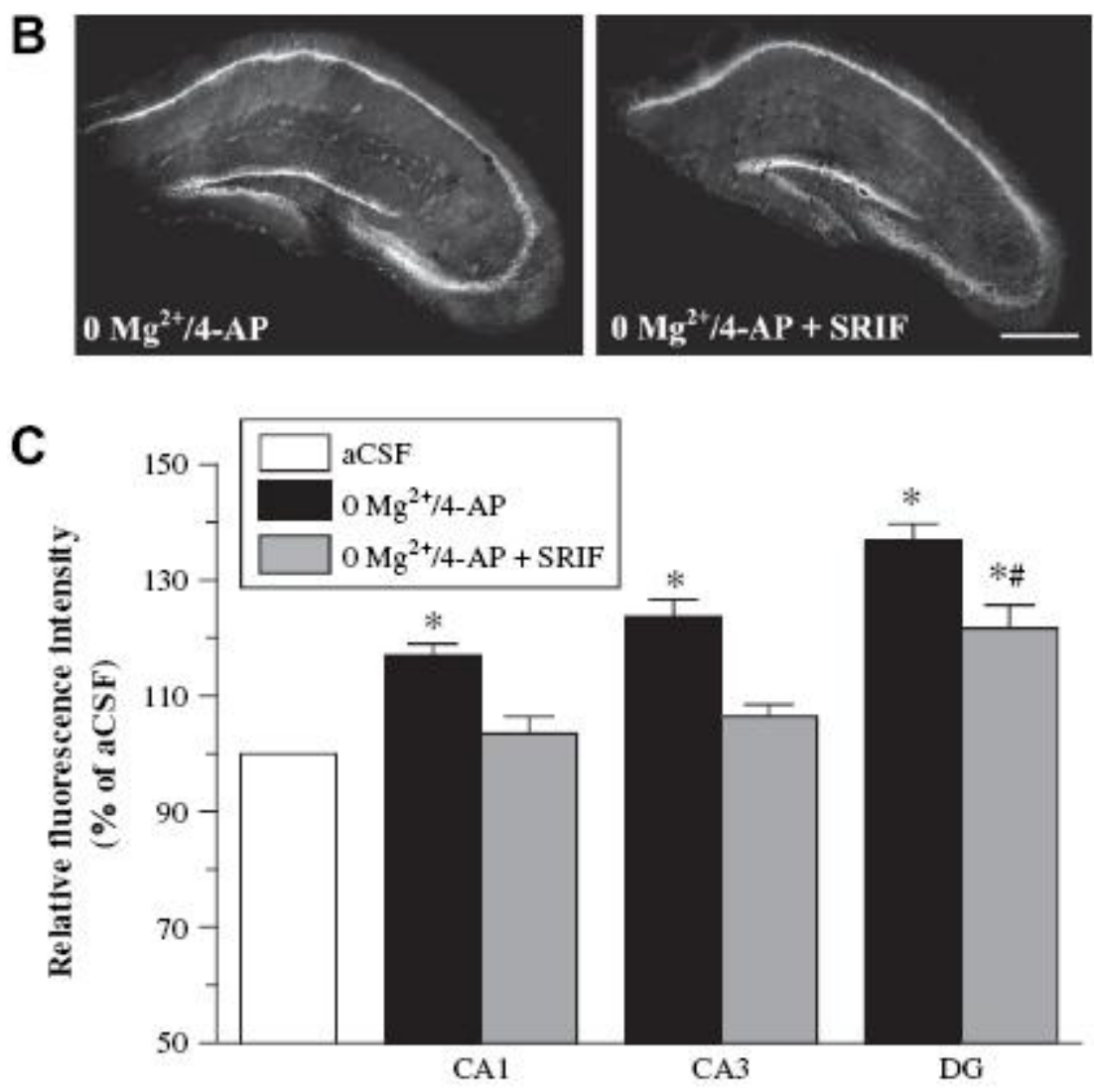

Fig. 2 


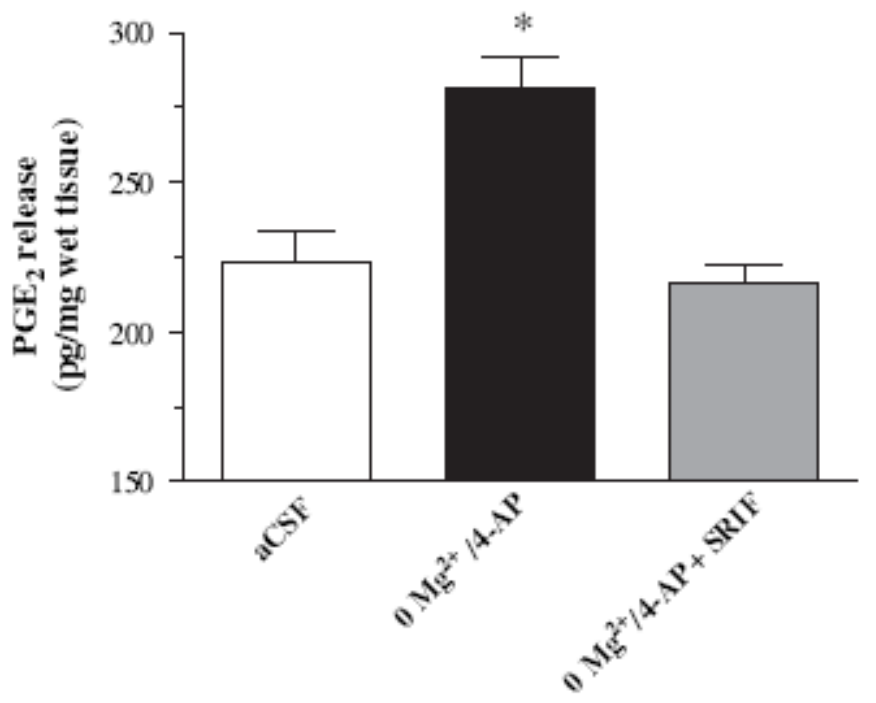

Fig. 3 

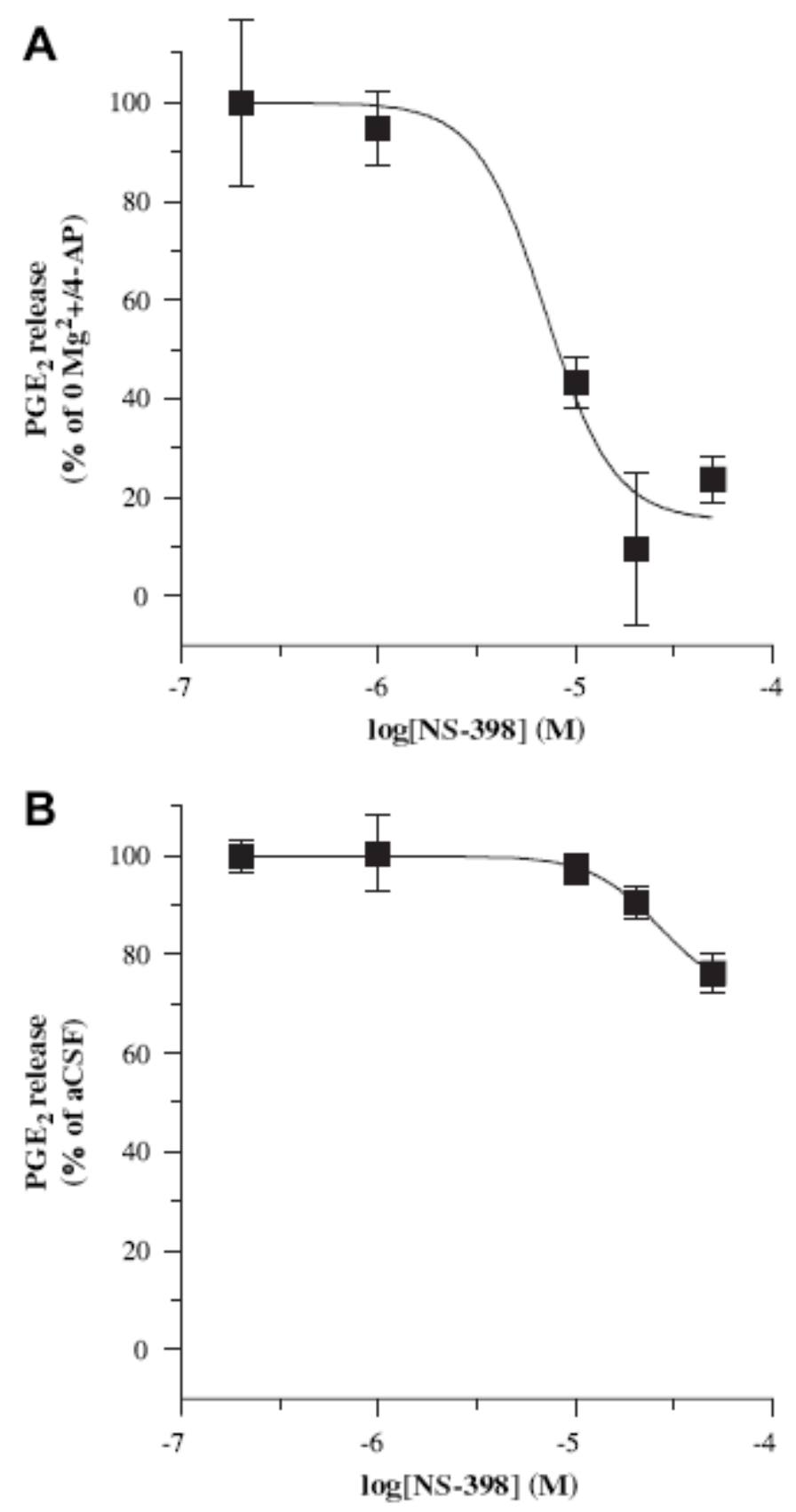

Fig.4 


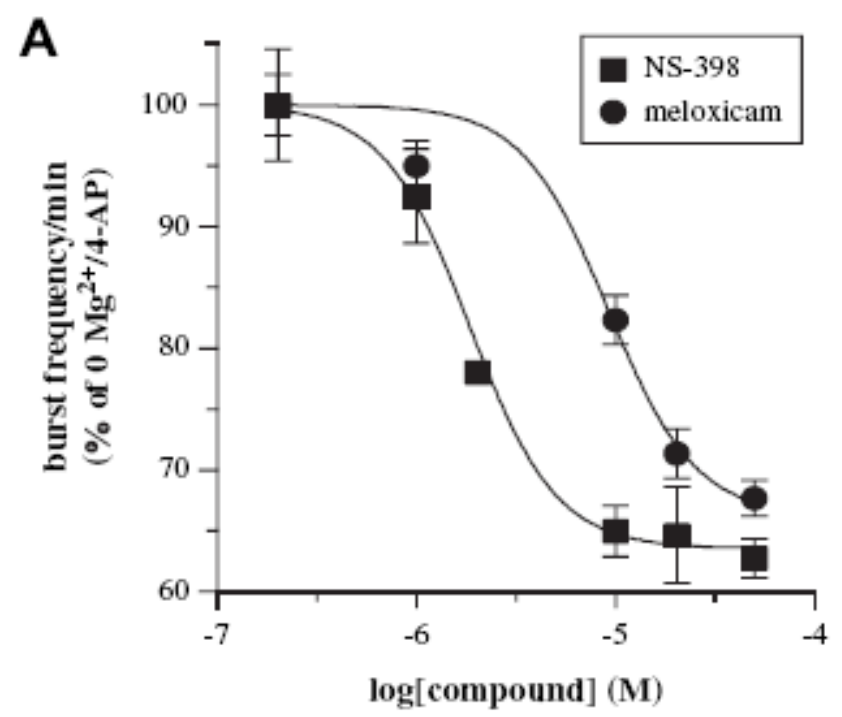

B

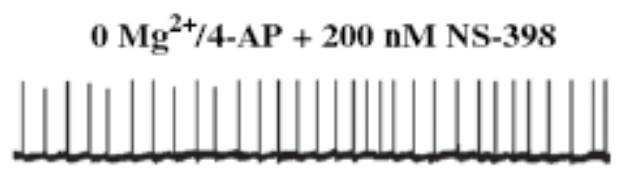

$0 \mathrm{Mg}^{2+} / 4-\mathrm{AP}+1 \mu \mathrm{M}$ NS-398

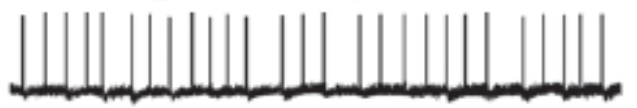

$0 \mathrm{Mg}^{2+} / 4-\mathrm{AP}+2 \mu \mathrm{M}$ NS-398

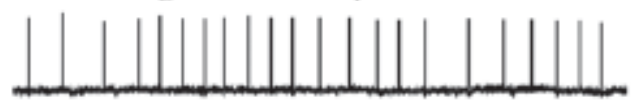

$0 \mathrm{Mg}^{2+} / 4-\mathrm{AP}+10 \mu \mathrm{M}$ NS-398

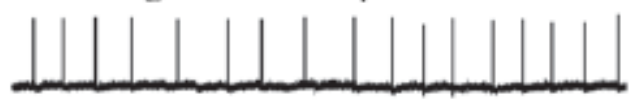

$0 \mathrm{Mg}^{2+} / 4-\mathrm{AP}+20 \mu \mathrm{M}$ NS-398

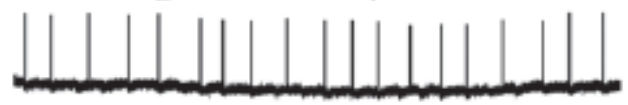

$0 \mathrm{Mg}^{2+} / 4-\mathrm{AP}+50 \mu \mathrm{M}$ NS-398
C $0 \mathrm{Mg}^{2+} / 4-\mathrm{AP}+200 \mathrm{nM}$ meloxicam

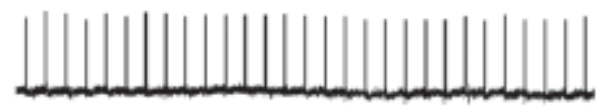

$0 \mathrm{Mg}^{2+} / 4-\mathrm{AP}+1 \mu \mathrm{M}$ meloxicam

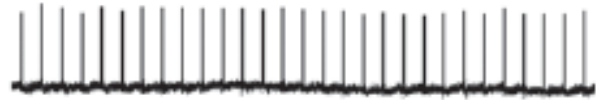

$0 \mathrm{Mg}^{2+} / 4-\mathrm{AP}+10 \mu \mathrm{M}$ meloxicam

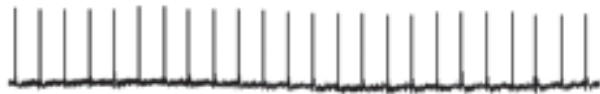

$0 \mathrm{Mg}^{2+} / 4-\mathrm{AP}+20 \mu \mathrm{M}$ meloxicam

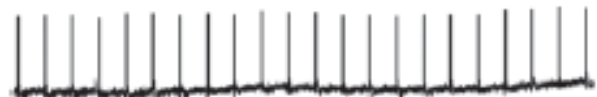

$0 \mathrm{Mg}^{2+} / 4-\mathrm{AP}+50 \mu \mathrm{M}$ meloxicam

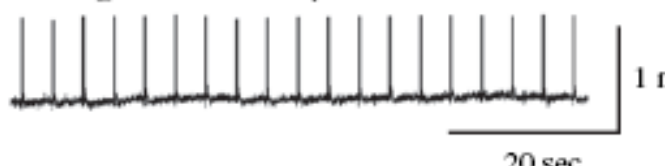

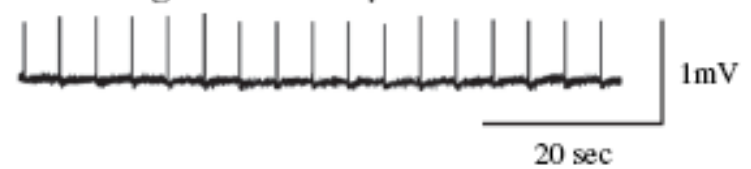

Fig.5 
A

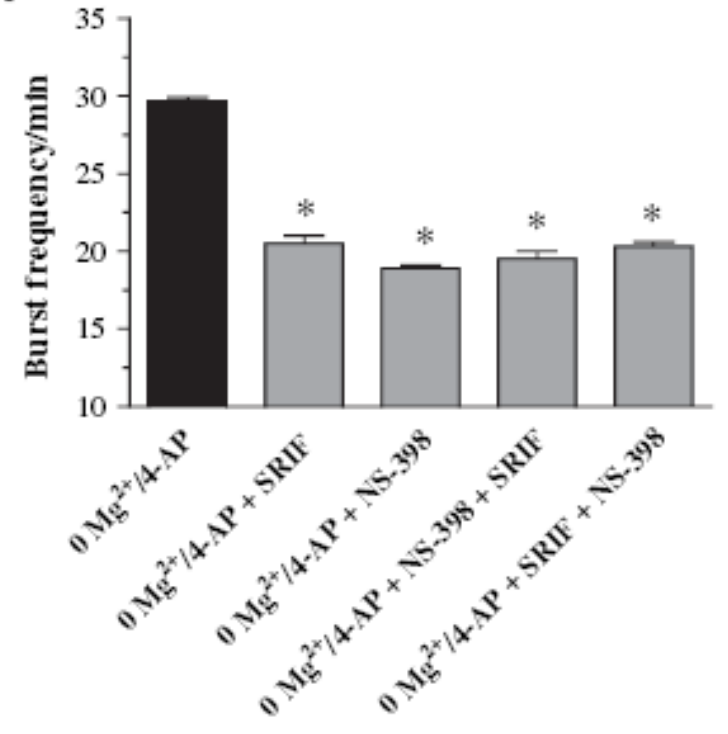

B

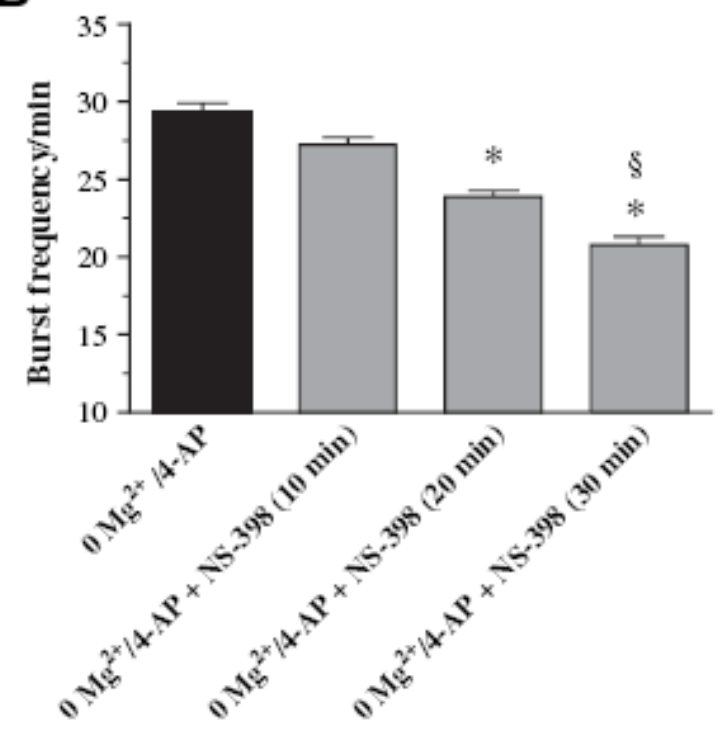

$0 \mathrm{Mg}^{2+} / 4-\mathrm{AP}$

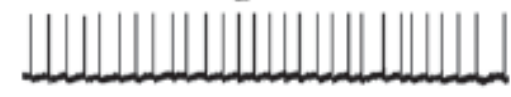

$0 \mathrm{Mg}^{2+} / 4-\mathrm{AP}+\mathrm{SRIF}$

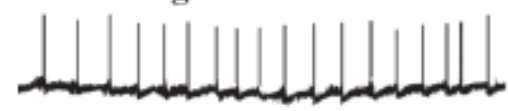

$0 \mathrm{Mg}^{2+} / 4-\mathrm{AP}+\mathrm{NS}-398$

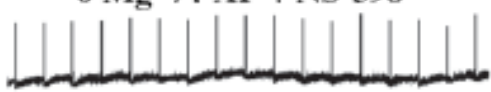

$0 \mathrm{Mg}^{2+} / 4-\mathrm{AP}+\mathrm{NS}-398+\mathrm{SRIF}$

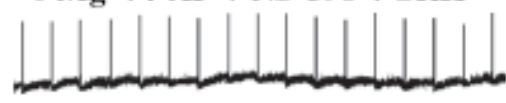

$0 \mathrm{Mg}^{2+} / 4-\mathrm{AP}+\mathrm{SRIF}+\mathrm{NS}-398$

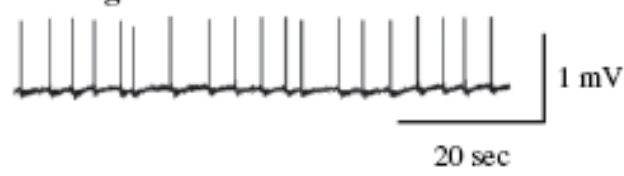

$0 \mathrm{Mg}^{2+} / 4-\mathrm{AP}$

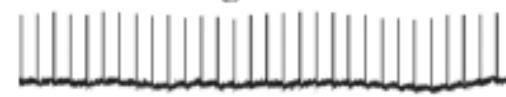

$0 \mathrm{Mg}^{2+} / 4-\mathrm{AP}+\mathrm{NS}-398(10 \mathrm{~min})$

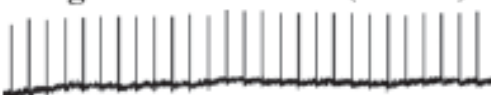

$0 \mathrm{Mg}^{2+} / 4-\mathrm{AP}+\mathrm{NS}-398(20 \mathrm{~min})$

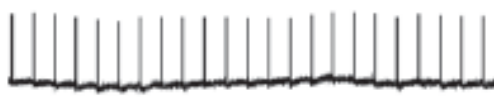

$0 \mathrm{Mg}^{2+} / 4-\mathrm{AP}+\mathrm{NS}-398(30 \mathrm{mln})$

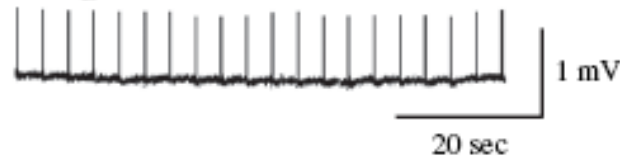

Fig.6 

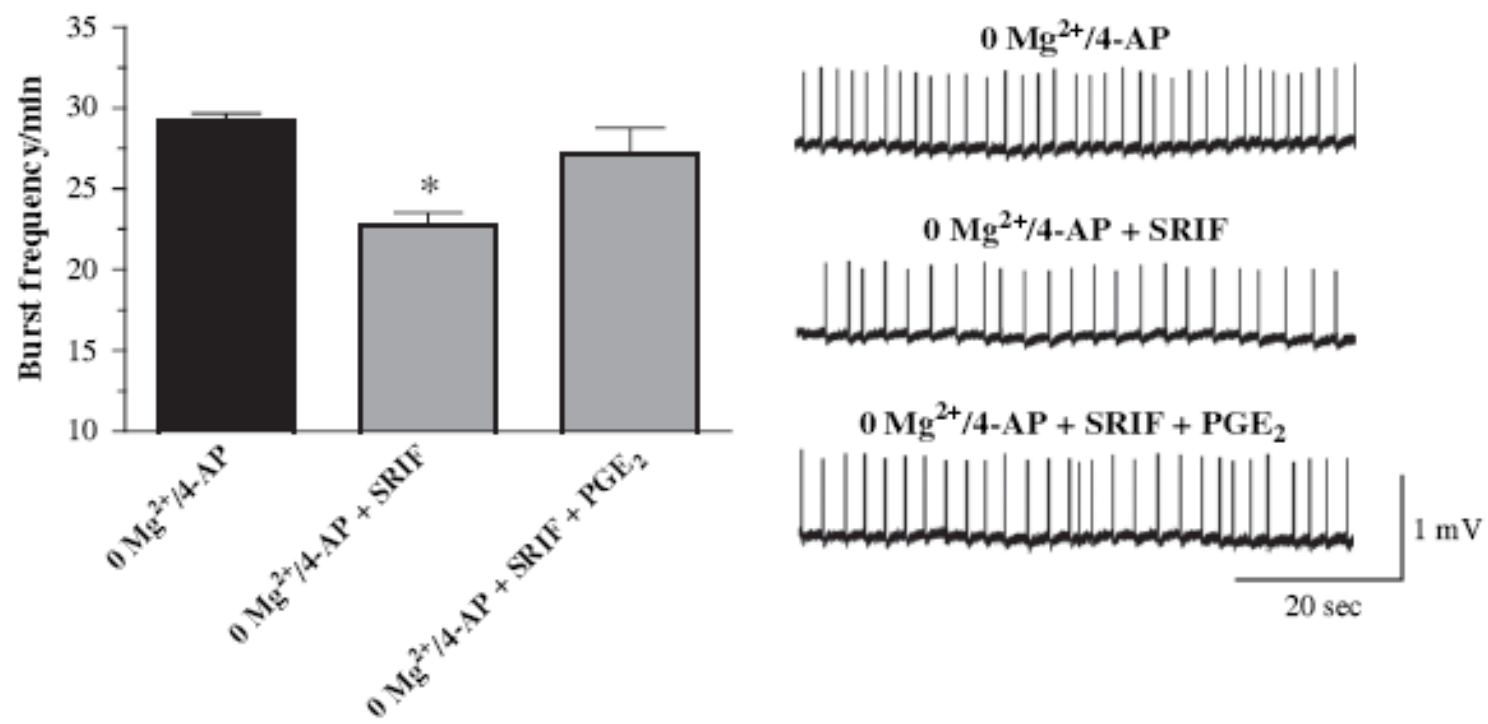

Fig. 7 